\title{
Intelligence: The Speed and Accuracy Tradeoff in High Aptitude Individuals
}

\author{
Suzanne P. Lajoie \\ University of Pittsburg \\ Bruce M. Shore \\ McGill University
}

\begin{abstract}
The relative contributions of mental speed and accuracy measures to Primary Mental Ability (PMA) IQ prediction were studied in 52 high ability students (mean age 16, mean IQ 120). Both speed and accuracy independently predicted $I Q$, but not speed over and above accuracy. Accuracy was demonstrated to be universally advantageous in IQ performance, but speed to vary according to the test. Superior performance might best be achieved by attention to accuracy at whatever speed the subject is comfortable working.
\end{abstract}

For many years theorists have struggled to define intelligence. One issue that remains controversial when describing intelligent performance is how mental speed contributes to $I Q$ test results. There is no doubt that a speed-accuracy tradeoff is involved in timed intelligence tests (Furneaux, 1960; Heim, 1970; Pachella, 1974; Pew, 1969). However, the nature of mental speed as it relates to high ability performance still needs to be described.

In learning new material or in recalling that previously learned, individuals who respond more quickly are often viewed as more intelligent (Spiegal \& Bryant, 1978). When laypersons were asked to generate a list of behaviors that characterize intelligence they provided answers such as, learns rapidly, acts, talks and makes judgments quickly (Sternberg, Conway, Ketron \& Bernstein, 1981). This assumption that "smart is fast" has fascinated psychologists as well.

Suzanne P. Lajoie received her M.A. from McGill University, is currently completing her Ph.D. at Stanford and is presently employed at the Learning Research and Development Center, University of Pittsburg. Bruce M. Shore, Ph.D. is Director of the Giftedness Center at McGill University. Reprints are available by writing Dr. Shore at 3700 McTavish, Montreal, Quebec, Canada, H3A 1 Y2.

Journal for the Education of the Gifted

Vol. IX, No. 2, 1986, pp. 85-104. Copyright (C) 1986, The Association for the Gifted, Reston, Virginia 22091. 
Historically, mental speed has been studied by differential psychologists in terms of speed factors, experimental psychologists with regard to simple and choice reaction times, pesonality psychologists with respect to cognitive styles such as reflection/impulsivity, and information-processing theories with reference to speed components or strategies. Although different methodologies have been used in these different schools of thought, the same implicit question has been asked about the importance of mental speed to intelligent performance.

Many studies have suggested a general speed component in measured intelligence (Dubois, 1932; Lord, 1956; McFarland, 1930; Miyajima, 1972; Porebski, 1954, 1960), however, Thurstone identified specific speed factors (Thurstone, 1939; 1944). In 1939 Thurstone specified nine Primary Mental Abilities (PMA), three of which were speed of mental processing factors: (a) perceptual speed, (b) speed of judgment and (c) speed and flexibility of closure. By 1944, Thurstone determined two more speed factors, reaction time and rate of reversals or alternations in perception. Speed of mental processing has also been described as a level within a hierarchy of aptitudes (Snow, 1978; Sternberg, 1977). Sternberg refers to speed as a strategic difference variable in his hierarchy of aptitudes. The issue is not whether there are one or more speed factors but, rather, how these factors affect IQ performance.

Experimental psychologists refer to mental speed in terms of reaction time. While mental events cannot be directly observed, their duration can be measured. Reaction time is taken to be the minimum amount of time needed to produce a correct response. Despite reaction-time research which suggests that speed can be studied as an isolated process, the speed-accuracy tradeoff controversy has revealed difficulties in separating speed from accuracy in measures of intelligence (Pachella, 1974). Researchers such as Eysenck (1967) and Jensen (1980) are still interested in what simple and choice reaction times can tell us regarding individual differences in intelligence. Simple reaction time refers to a single reaction to a single stimulus, in contrast to choice reaction time where the subject must make a differential response depending on which one or combination of stimuli are presented. Choice reaction times have been more highly correlated with conventional tests of intelligence than simple reaction-time tests.

Speed and accuracy have also become linked with two rather value-laden constructs, reflection and impulsivity, which refer to speed of judgment in problems of response uncertainty (Kagan, 
Moss \& Siegel, 1963). A dual index with median splits on speed and accuracy was created to differentiate individuals into four categories as determined by the Matching Familiar Figures Test (Kagan, Pearson $\&$ Welch, 1966). The four groups are decribed as reflectives (slow accurates), slow inaccurates, impulsives (fast inaccurates), and fast accurates. Research related to these cognitive styles has attempted to decribe the relations between speed and intelligence (see Messer, 1976 for a summary of this work), however, the majority of this work has concentrated on young children and mainly on the differences between reflectives and impulsives, neglecting the other two categories. An interesting part of this research explores the possibility that being slow by way of not making snap judgments is not always efficient, just as being quick can lead to careless mistakes. The importance of speed to accuracy can vary according to the task demands and the individual.

Information-processing studies have also examined speed in relationship to intelligence. High scorers on the Washington Pre-College Test were found to search short term memory faster than low scorers (Hunt, Frost \& Lunneborg, 1973). Similarly, high verbals access highly overlearned material in long term memory more rapidly than low verbals in both visual and auditory modalities (Goldberg \& Schwartz, 1977; Hunt, Frost \& Lunneborg, 1973; Hunt, Lunneborg \& Lewis, 1975). Among children with average and very high IQ levels on picure and word classification tasks, the high group was significantly faster on the word-pair test (Hermelin \& O'Connor, 1979). Sternberg (1984) reviewed studies on reasoning behavior in children and adults and found that higher ability is associated with rapid execution of most information-processing components except for encoding (see Mulholland, Pelegrino \& Glase, 1980; Sternberg, 1977). Presumably, longer encoding times fascilitate subsequent operations. Another area of research where slowness is preferable to quickness is on insight problems. Sternberg \& Davidson (1982) found that people who spent more time on insight problems had a higher number of correct solutions and higher IQ scores; "high aptitude individuals, who presumably have more elaborate semantic memory structures, may encode more item features and take more time in this aspect of processing, but with subsequent facilitation in the speed and accuracy of selection among alternatives" (Pelegrino \& Glaser, 1979, also referring to Sternberg, 1977). Once again, the results relating speed to intelligence are mixed.

The current study examines different tests of mental speed taken from these various perspectives and uses them as a mental speed 
test battery to compare the relations between these measures and a traditional IQ measure, the Primary Mental Abilities Test (PMA). There is still a gap in the literature as to how to isolate a pure mental speed characteristic from accuracy when examining the relation of speed to measured intelligence. Speed and accuracy components should be considered separately to determine which most influences the total score (Carroll \& Maxwell, 1979). This study attempts to bridge the gap between speed and accuracy in order to explain the influence of speed on intelligent performance.

\section{Method}

Fifty-two grade ten subjects in two English classes participated in this study, 18 girls and 34 boys (mean age 16-1; range 14-8 to 18-9). The students were predominantly English-speaking from middle-income families in a suburb of Montreal. The mean IQ of this sample measured by the Primary Mental Abilities Test (PMA) was 120.3 (s.d. $=15.1$ )

Individual testing was conducted in a small room within the school and required, on the average, 70 minutes per student on consecutive days. Group testing occurred on three consecutive days during students' regular English classes. There were no missing data. Subjects were informed about the nature of the study after completing the test battery.

\section{Results}

Descriptive statistics on the sample revealed that there were neither significant sex differences on the criterion (PMA) test nor between the two grade 10 classes on the overall score $(t(50)=2.21, p$ $>$.01). Significant differences between the two classes were found on three subtests of the PMA. Class A scored significantly higher than class $B$ on Word Fluency $(t(50)=2.92, p>.005)$, Verbal Meaning $(t(50)=3.03, p .004)$ and Reasoning $(t(50)=2.68, p<$ $.01)$. These differences were not explored further since they were not tied to the present research question. The two classes were considered as one group in the following analyses.

In order to test how speed or accuracy predicted general intellectual ability, a multiple univariate regression analysis was conducted under the analysis of covariance model (Finn, Program Version 5.2, 
1977). All 11 speed predictors (identified by the code " $a$ " in column one of Table 1) were entered at once into the regression equation, in effect treating them as if collapsed into one independent speed variable, and all 14 accuracy predictors (identified by the code " $b$ ") were similarly regarded as one independent accuracy variable. Table 2 demonstrates that $34 \%$ of the speed measures were significantly correlated with the intelligence measures, as were $67 \%$ of the accuracy measures. However, only $13 \%$ of the speed and accuracy measures were significantly intercorrelated. This relative independence of the two sets of measures reflects well on the choice of tests and aids in discussing separately the results for speed and accuracy. While large numbers of independent measures should not be administered to only 52 subjects, the effect is to provide diverse tests of mental speed and accuracy to see whether there is a way to follow Carroll \& Maxwell's (1979) suggestion regarding isolating speed from accuracy components in intelligence. In this way, the global contributions of mental speed and accuracy to IQ performance were examined. Raw, stanine and IQ scores were examined; only raw score data are reported since comparable results were found with the other two analyses.

Speed predictors ordered first. The speed predictors were ordered first for this set of analyses since the main issue is the contribution of speed to IQ. The criterion variable was the total raw score obtained on the PMA. The results of this analysis are found in Table 3. The squared multiple $R$ indicated that $67 \%(p<.0001)$ of the total PMA raw score variance could be predicted by the speed predictors alone. The speed plus accuracy predictors alone were found to account for $89 \%$ ( $p<.0001)$.

In order to more precisely assess the contribution of speed to the prediction of separate cognitive abilities, multiple multivariate regression analyses were performed. The criterion variables were the five subtests of the PMA: Word Fluency, Verbal Meaning, Number Facility, Reasoning and Spatial Relations. The same two sets of predictor variables were utilized. A summary of the results is presented in Table 4.

A multivariate $F$ test indicated that speed plus accuracy could together significantly predict performance on the total five PMA subtests $(p<.003)$. Univariate $F$ tests for the separate criterion subtests, however, indicated that speed and accuracy could together significantly predict performance only on Verbal Meaning $(p<$ $.0001)$ and Spatial Relations $(p<.01)$, but not on the other three.Speed alone was found to significantly predict performance on 


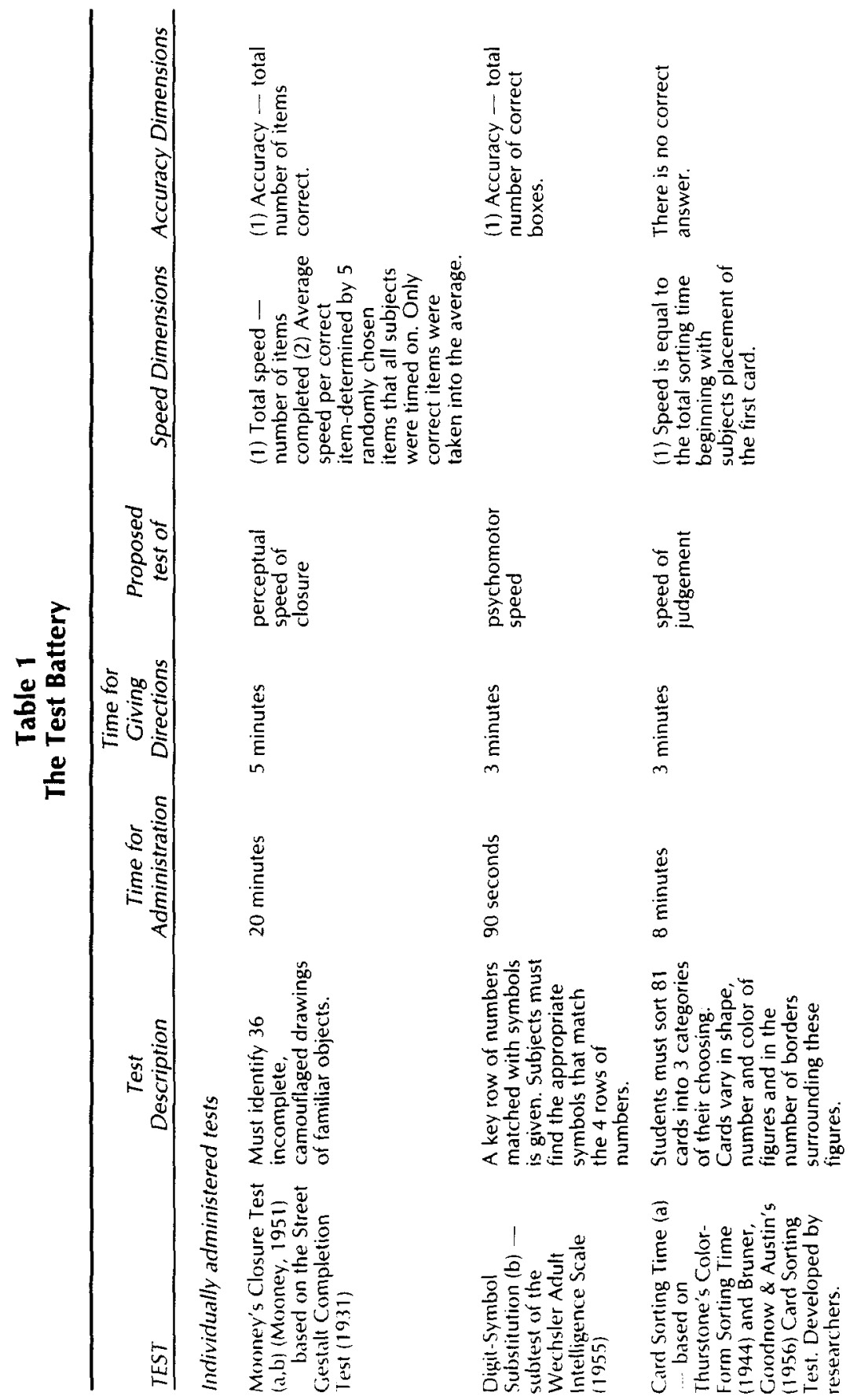




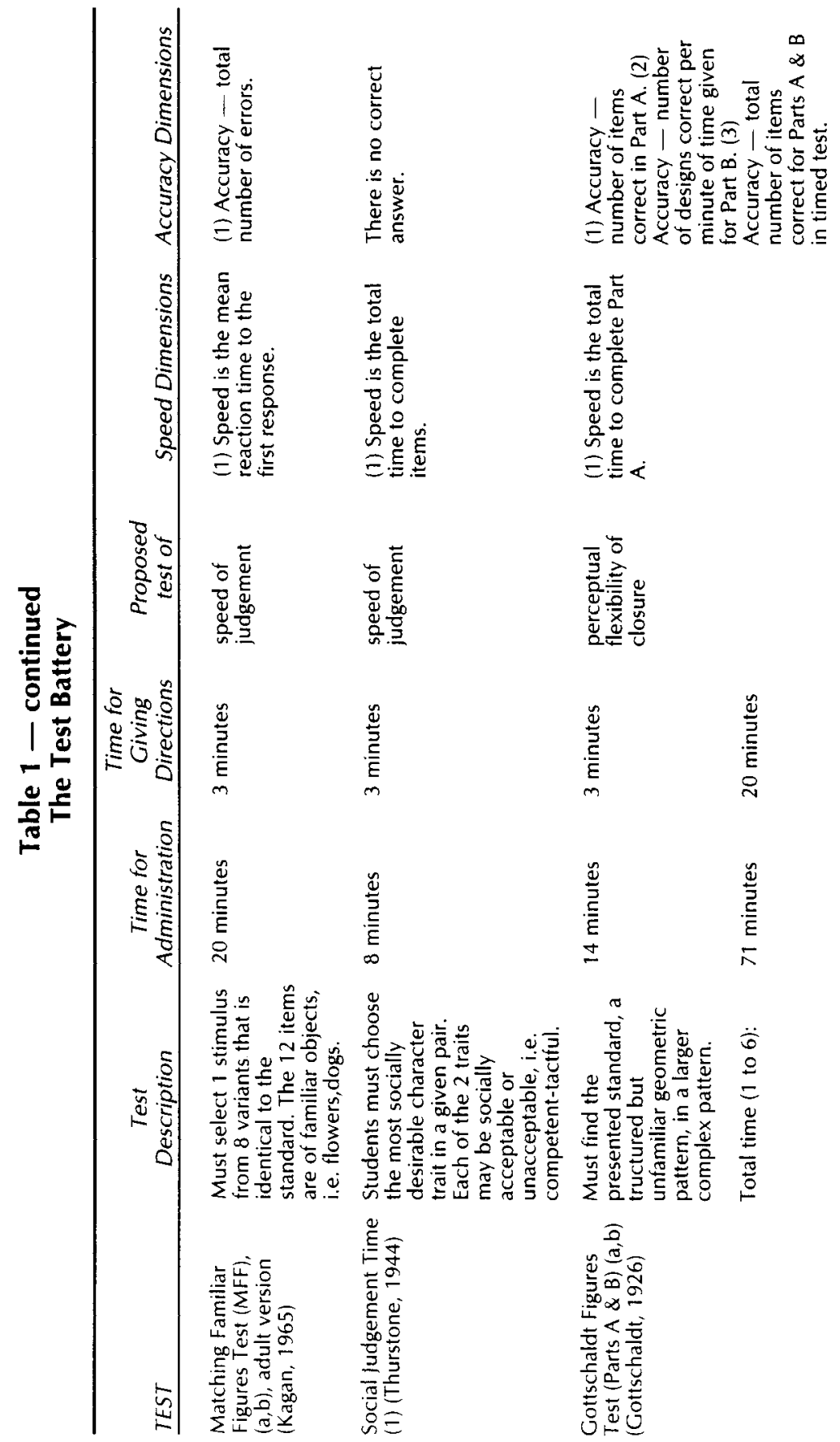




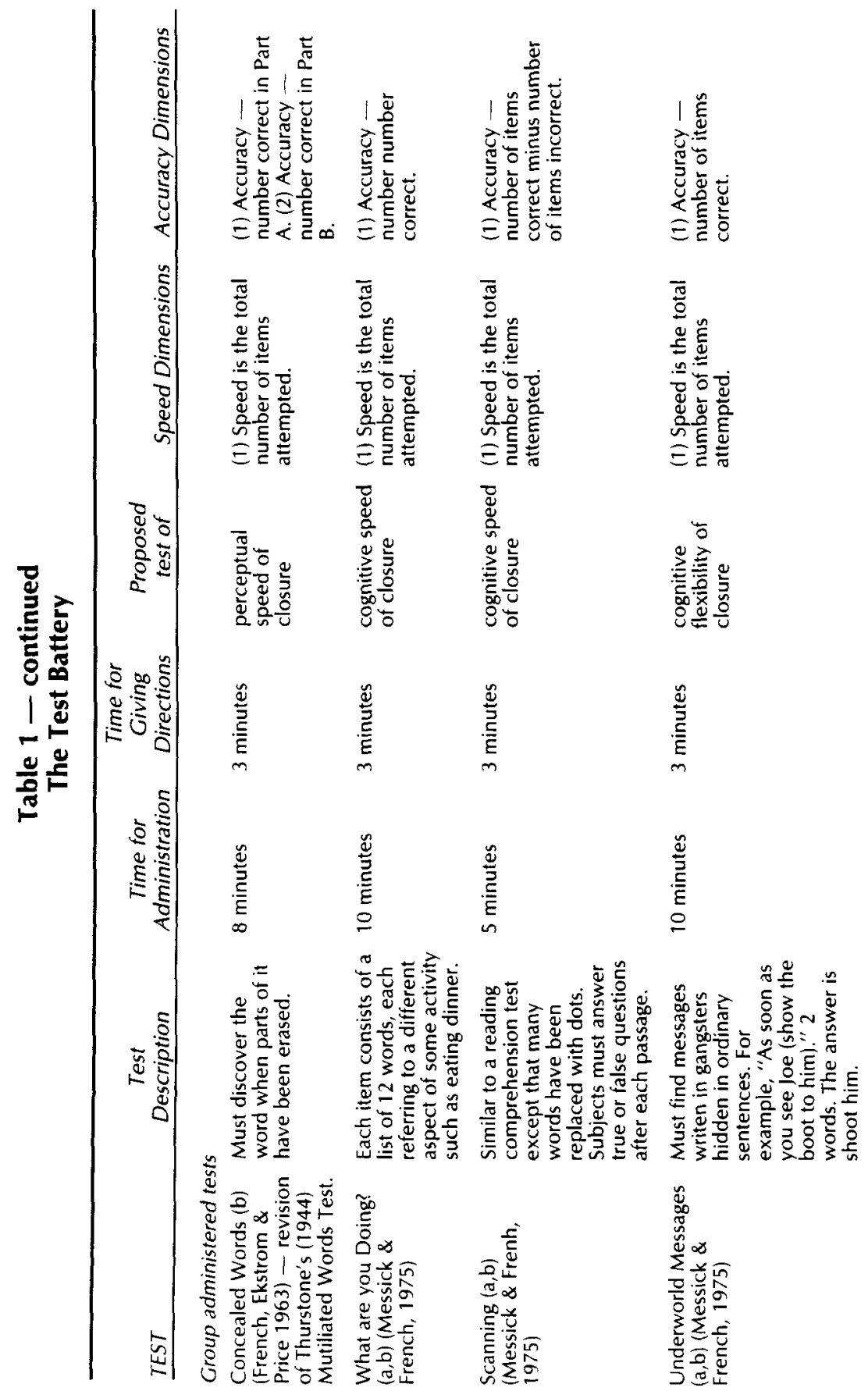




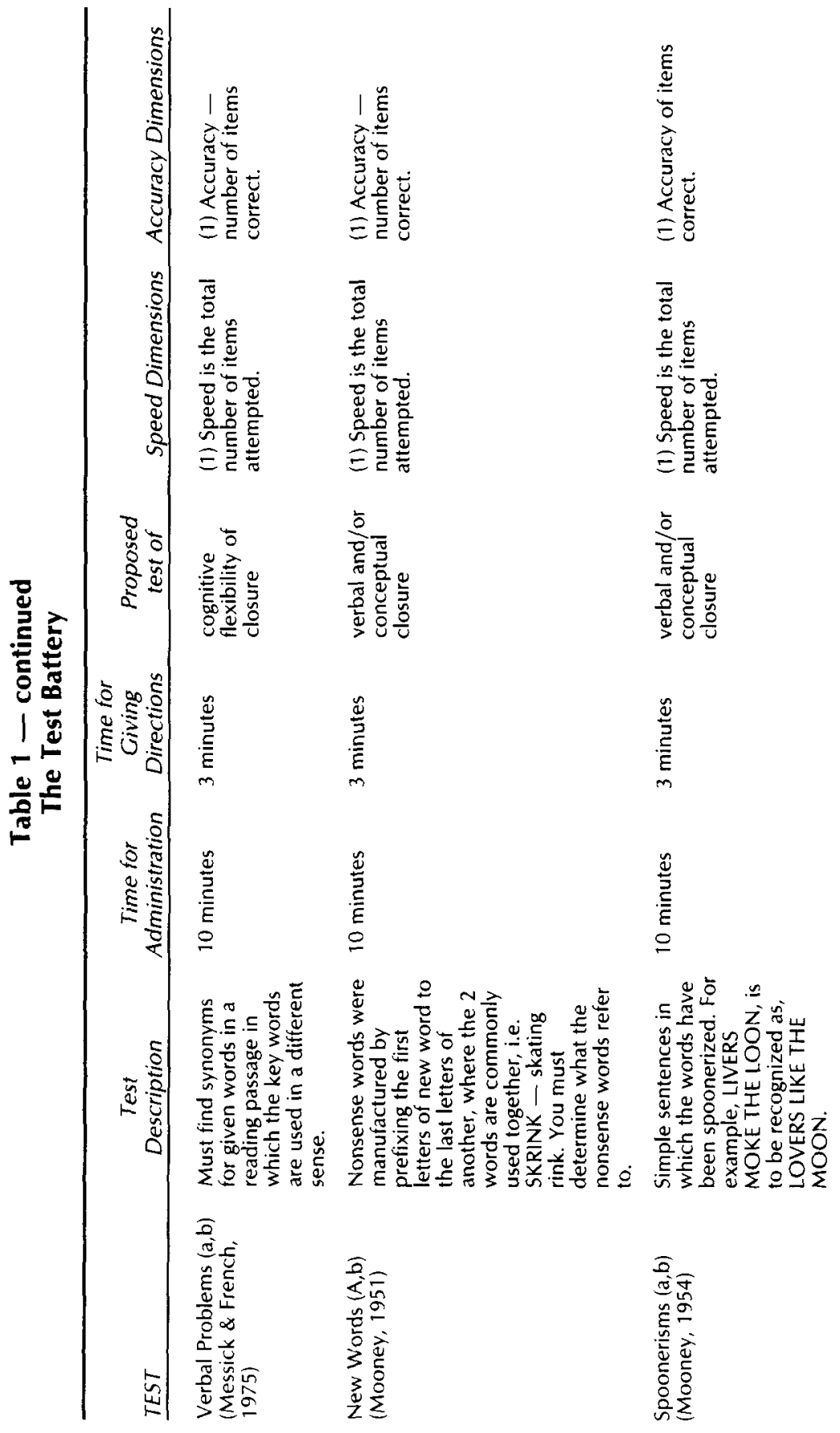




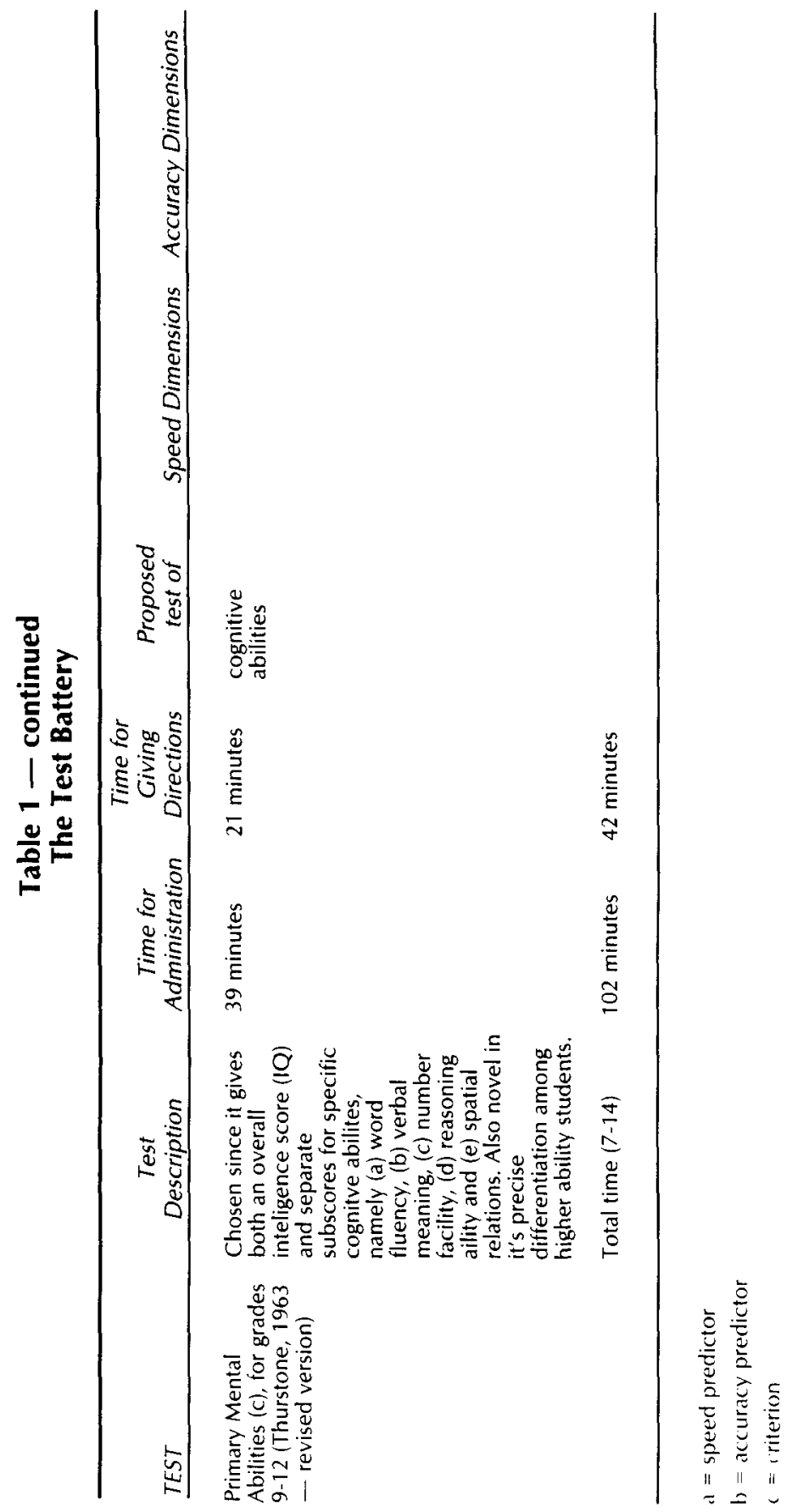


the full set of subtests $(p<.0001)$, and on every subtest. The proportions of additional variance accounted for by univariate $F$ tests are shown in Table 4. Adding the accuracy predictors to the regression equation did not significantly improve the prediction of the set of subtest scores $(p>.01)$

Accuracy predictors ordered first. A separate analysis was performed to determine whether or not the order of predictor variables into the multiple regression equation would greatly affect the results. When accuracy predictors were entered first they determined $83 \%$ of the variance of the total raw PMA scores $(p<.0001)$. However, speed was not found to contribute further after accuracy was taken into consideration $(p>.01)$.

These findings lend additional support for accuracy having priority over speed in accounting for intelligence test variance. At the same time, the square multiple $R$ and correlation matrix show speed and accuracy to be quite highly intercorrelated, indicating that these variables should not be looked at only in terms of their independent contributions to the measurement of intelligence.

The results of the multiple multivariate regression analysis using accuracy predictors ordered first are found in Table 5. The multivariate $F$ tests indicate that the set of speed and accuracy predictors could significantly predict performance on the five PMA subtests $(p$ $<$. 0003). The $F$ tests for the separate IQ subtests indicated that speed and accuracy could only predict performance on Verbal Meaning $(p<.0001)$ and Spatial Relations, $(p<.01)$; for all other relations, $p>.01$.

Accuracy significantly predicted performance on the set of five subtests $(p<.0001)$ and on each subtest. Adding the speed predictors to the regression did not significantly add to predicting the set of subtest scores $(p>.01)$. These results exactly mirror the pattern obtained when speed was entered first.

The results indicate that both speed and accuracy contribute to the PMA IQ and certain subtests. The amount of this contribution varied according to which predictor was ordered first, and the percentage of variance accounted for by accuracy (see Tables 2 and 5) was higher.

A close examination was made of the types of speed and accuracy subtests which were significantly correlated with the PMA subscores (cf. Table 2). As noted earlier, the correlations between the measures of speed and intelligence, $33.5 \%$ were significant at the .01 level, as were $67.4 \%$ of the correlations between measures of accuracy and intelligence. As found in other studies, all PMA subtests were signifi- 


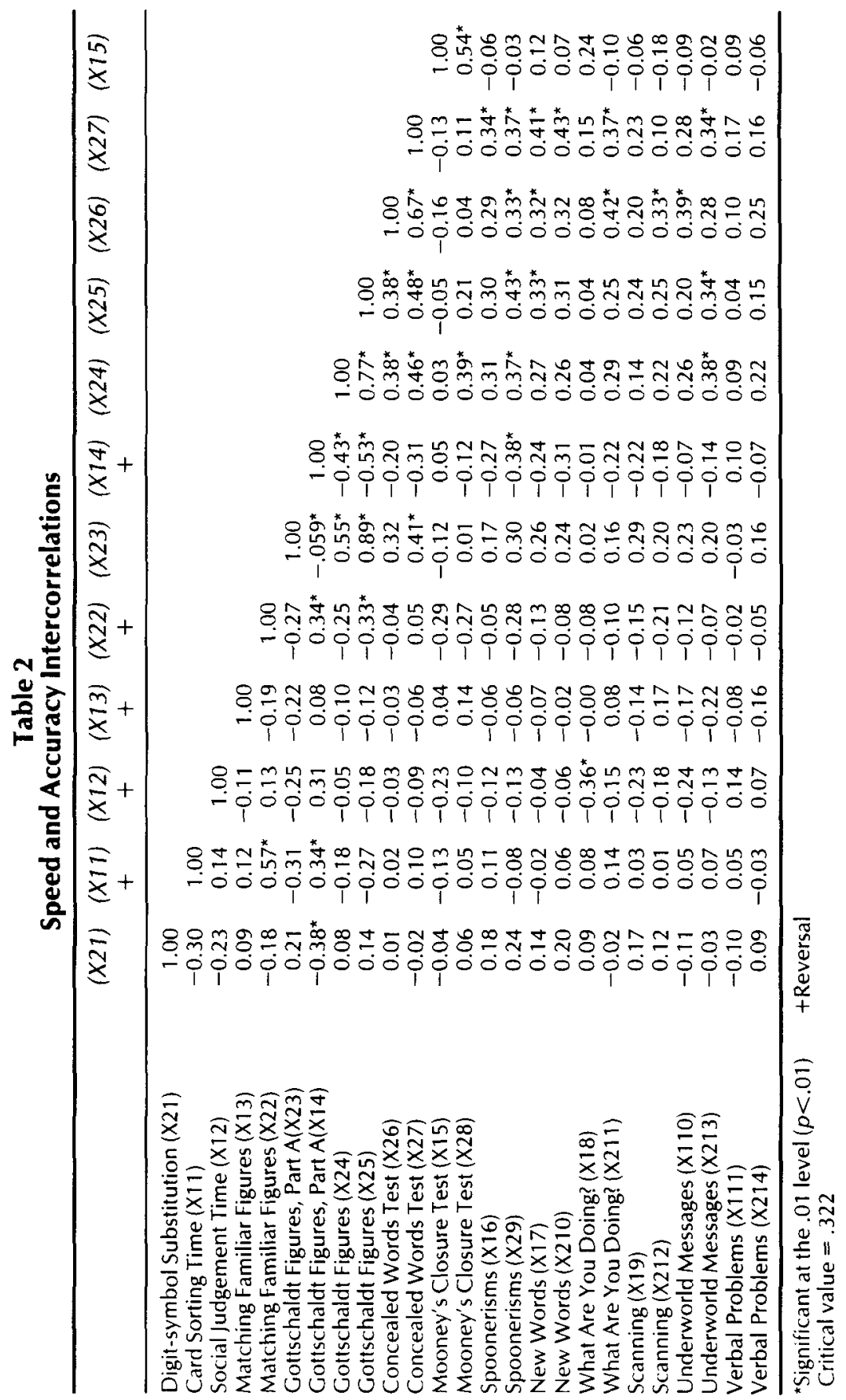




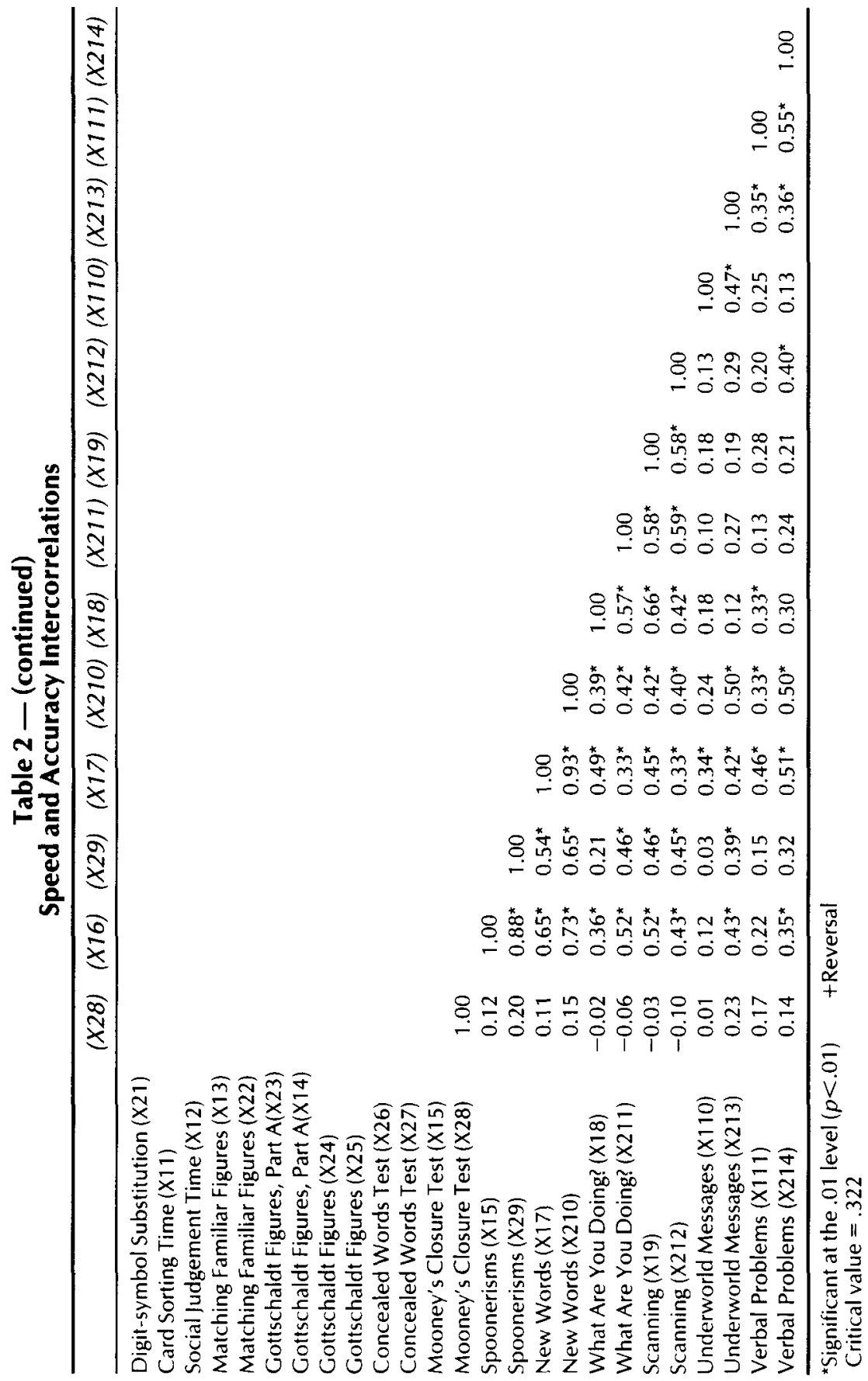


Table 3

The Effects of Ordering in Two Step-up Univariate Multiple Regression Analyses

\begin{tabular}{|c|c|c|c|c|}
\hline Source of Variation & $\begin{array}{l}\text { Criterion } \\
\text { Variables }\end{array}$ & Multiple $\mathrm{R}$ & $\begin{array}{l}\text { Degrees of } \\
\text { Freedom }\end{array}$ & $\begin{array}{l}\text { Multi- } \\
\text { variate } \mathrm{F}\end{array}$ \\
\hline $\begin{array}{l}\text { Speed as the first } \\
\text { variable entered } \\
\text { Speed + Accuracy } \\
\text { ( } 25 \text { measures) }\end{array}$ & $\begin{array}{l}\text { Primary } \\
\text { mental } \\
\text { abilities } \\
\text { (total raw } \\
\text { score) }\end{array}$ & $0.8857^{\star \star \star}$ & 25,23 & 7.129 \\
\hline $\begin{array}{l}\text { Speed alone } \\
\text { (11 measures) }\end{array}$ & $\begin{array}{l}\text { Primary } \\
\text { mental } \\
\text { abilities } \\
\text { (total raw } \\
\text { score) }\end{array}$ & $0.6734^{\star \star \star}$ & 11,37 & 6,934 \\
\hline $\begin{array}{l}\text { Further contribution } \\
\text { of accuracy } \\
\text { ( } 14 \text { measures) }\end{array}$ & $\begin{array}{l}\text { Primay } \\
\text { mental } \\
\text { abilities } \\
\text { (total raw } \\
\text { score) }\end{array}$ & $0.2123^{\star}$ & 14,23 & 3,052 \\
\hline $\begin{array}{l}\text { Accuracy as the first } \\
\text { variable entered } \\
\text { Accuracy alone } \\
\text { (14 measures) }\end{array}$ & $\begin{array}{l}\text { Primary } \\
\text { mental } \\
\text { abilities } \\
\text { (total raw } \\
\text { score) }\end{array}$ & $0.8292^{\star \star \star}$ & 14,34 & 11.789 \\
\hline $\begin{array}{l}\text { Further contribution } \\
\text { of speed } \\
\text { (11 measures) }\end{array}$ & $\begin{array}{l}\text { Primary } \\
\text { mental } \\
\text { abilities } \\
\text { (total raw } \\
\text { score) }\end{array}$ & 0.0565 & 11,23 & 1.033 \\
\hline
\end{tabular}

${ }^{\star} p<.01$

${ }^{* *} p<.0001$

cantly intercorrelated. Both the speed and accuracy measures of the Gottschaldt Figures, Spoonerisms, New Words, What Are You Doing?, Scanning, Underworld Messages and Verbal Problems tests were significantly correlated with the PMA subtests. These same speed and accuracy measures were significantly intercorrelated. 
Table 4

Multiple Multivariate Regression Analysis with Speed Entered First in the Equation

\begin{tabular}{|c|c|c|c|c|}
\hline Source of Variation & $\begin{array}{l}\text { Criterion } \\
\text { Variables }\end{array}$ & Multiple R & $\begin{array}{l}\text { Degrees of } \\
\text { Freedom }\end{array}$ & $\begin{array}{l}\text { Multi- } \\
\text { variate F }\end{array}$ \\
\hline $\begin{array}{l}\text { Speed + Accuracy } \\
\text { (25 measures) }\end{array}$ & $\begin{array}{l}\text { Word Fluency } \\
\text { Verbal Meaning } \\
\text { Number Facility } \\
\text { Reasoning } \\
\text { Spatial } \\
\text { Relations }\end{array}$ & $\begin{array}{l}0.6350 \\
0.8743^{\star \star \star} \\
0.6814 \\
0.7094 \\
0.7458^{\star \star}\end{array}$ & 125,98 & $1.9762^{\star \star}$ \\
\hline $\begin{array}{l}\text { Speed } \\
\text { (11 measures) }\end{array}$ & $\begin{array}{l}\text { Work Fluency } \\
\text { Verbal Meaning } \\
\text { Number Facility } \\
\text { Reasoning } \\
\text { Spatial } \\
\text { Relations }\end{array}$ & $\begin{array}{l}0.5217^{\star} \\
0.7094^{\star \star \star} \\
0.5260^{\star \star} \\
0.4961^{\star} \\
0.4219\end{array}$ & 55,156 & $2.3383^{\star \star \star}$ \\
\hline $\begin{array}{l}\text { Accuracy } \\
\text { (14 measures) }\end{array}$ & $\begin{array}{l}\text { Word Fluency } \\
\text { Verbal Meaning } \\
\text { Number Facility } \\
\text { Reasoning } \\
\text { Spatial } \\
\text { Relations }\end{array}$ & $\begin{array}{l}0.1133 \\
0.1649 \\
0.1554 \\
0.2133 \\
0.3239\end{array}$ & 70,95 & 1.4079 \\
\hline
\end{tabular}

${ }^{\star} p<.01$

$\star \star *<<.001$

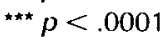

\section{Discussion}

Mental speed was significantly related to general intelligence as measured by the total PMA score and to specific subtests, namely, Word Fluency, Verbal Meaning, Reasoning, Number Facility and Spatial Relations. However, accuracy was more highly related than speed to performance on the PMA and most of its subtests. Accuracy added significantly to $I Q$ predictions by speed, whereas the reverse was not observed. Earlier studies of mental speed suggested that true measures of speed were confounded by accuracy scores (Furneaux, 1960). The present study supports the idea that speed and accuracy should be looked at independently in an able sample. That a speed-accuracy tradeoff (Heim, 1970; Pew, 1969) exists in IQ tests is not disputed. 
Table 5

Multiple Regression Analysis With Accuracy Entered First in the Equation

\begin{tabular}{|c|c|c|c|c|}
\hline Source of Variation & $\begin{array}{l}\text { Criterion } \\
\text { Variables }\end{array}$ & Multiple R & $\begin{array}{l}\text { Degrees of } \\
\text { Freedom }\end{array}$ & $\begin{array}{l}\text { Multi- } \\
\text { variate } \mathrm{F}\end{array}$ \\
\hline $\begin{array}{l}\text { Speed + Accuracy } \\
\text { ( } 25 \text { measures) }\end{array}$ & $\begin{array}{l}\text { Word Fluency } \\
\text { Verbal Meaning } \\
\text { Number Facility } \\
\text { Reasoning } \\
\text { Spatial } \\
\text { Relations }\end{array}$ & $\begin{array}{l}0.6350 \\
0.8743^{\star \star \star} \\
0.6814 \\
0.7094 \\
\\
0.7458^{\star \star}\end{array}$ & 125,98 & $1.9762^{\star \star}$ \\
\hline $\begin{array}{l}\text { Accuracy } \\
\text { (14 measures) }\end{array}$ & $\begin{array}{l}\text { Word Fluency } \\
\text { Verbal Meaning } \\
\text { Number Facility } \\
\text { Reasoning } \\
\text { Spatial } \\
\text { Relations }\end{array}$ & $\begin{array}{l}0.5280^{\star} \\
0.7342^{\star \star \star} \\
0.6039^{\star \star} \\
0.5732^{\star} \\
0.6495^{\star \star}\end{array}$ & 70,147 & $2.6794^{\star \star \star}$ \\
\hline $\begin{array}{l}\text { Speed } \\
\text { (11 measures) }\end{array}$ & $\begin{array}{l}\text { Word Fluency } \\
\text { Verbal Meaning } \\
\text { Number Facility } \\
\text { Reasoning } \\
\text { Spatial } \\
\text { Relations }\end{array}$ & $\begin{array}{l}0.1070 \\
0.1400 \\
0.0775 \\
0.1362 \\
0.0963\end{array}$ & 55,92 & 1.0485 \\
\hline
\end{tabular}

It seems reasonable to conclude that there are different types of speed of mental processing, some of which contribute to performance on a standard intelligence test and some that do not. It may be just as important to examine those tests of speed which were not related to standard intelligence tests (speed of judgement and speed of closure in this study) since they may be contributing to abilities not usually measured by standard intelligence tests. A future study might also follow up the nonsignificant directional differences found between certain speed measures and the PMA: "slowness" on some measures was, in fact, more related to intellectual performance than "quickness."

It has been suggested earlier that speed and accuracy components of performance on an intelligence test be considered separately in order to determine which of these different aspects of a subject's performance influences the majority of the total score (Carroll \& Maxwell, 1979). The present study suggests that the answer might be 
that both contribute to intelligence and in different ways. Perhaps accuracy measures are generally related to IQ test performance in contrast to the task-specific relationship between mental speed and intelligence. The relation of accuracy to IQ may be linear, but that of speed nonlinear, in other words, accuracy should be maximized and speed optimized. Both speed and accuracy independently contribute to performance on an intelligence test, accuracy significantly adds to the prediction of PMA performance by speed alone, but not speed in addition to accuracy. These observations suggest that future research should consider speed of mental processing from new perspectives. Carroll and Maxwell's (1979) idea of reclassifying the speed elements into a separate cognitive speed domain should be considered and possibly initiated by examining those speed tests which, in the present study, were or were not highly correlated with the PMA.

It is reasonable to conclude that there is sometimes something behind the statement that being "quick" is related to being intelligent, but not always. Future studies might benefit from a more process-oriented approach to the study of speed of mental processing. Some of the questions that need to be answered are the following. Why is quickness important to accuracy on some tasks, slowness on others? What types of tasks require fast processing, which require slow processing? Can strategies of quickness and slowness be taught to students so that they can utilize them for optimal performance? Are there some individuals who have the metacognitive ability to select the proper strategy, speed on some tasks, slowness on others, and are they perhaps the high ability scorers across a variety of intellience and ability measures?

Perhaps what is critical to good performance is not speed as such but, rather, speed selection (Sternberg, 1984). Sternberg (1977, 1984) and Pellegrino and Glaser (1979) suggested that initial slower processing speed by high aptitude individuals should enhance both speed and accuracy of later selection processes. The present results might point to a slight favoring of accuracy in their functioning.

This article has implications for professional educators and others. It reiterates that individual differences of a qualitative nature exist even at higher levels of ability. A group having high scores on an ability test (or sharing any indicator of giftedness) is not homogeneous. Children have different learning styles and speeds, and individual children may vary in style and speed on different tasks. High scores, for example, only tell us about high accuracy in performance, but little about how that accuracy was achieved. 
Educators commonly instruct children to slow down in order to perform well, to be reflective. It should be surprising, at least, to discover that $67 \%$ of the total variance of the PMA IQ score can be attributed to the speed of reply in some form, and more often quickness than slowness among the measures in this study. The corresponding figure for accuracy was $83 \%$. We ask children to slow down and then test them with speeded tasks when unspeeded tests might be a fairer assessment of students' abilities in those circumstances. Some people perform well in speeded tasks. Speed is an advantage on some tasks, a disadvantge on others. It may be more appropriate to teach children to discriminate that there are tasks where being quick is an advantage and others where it is not. Superior performance, therefore, might best be achieved by attention to accuracy at whatever speed the student is comfortable working.

\section{Note}

* This research was supported by a grant from the Government of Quebec "FCAC" program.

\section{References}

Caroll, J., \& Maxwell, S. E. (1979). Individual differences in abilities. Annual Review of Psychology, 30, 603-640.

Dubois, P. H. (1932). A speed factor in mental test. Archives of Psychology, $141,5-38$.

Eysenck, H. J. (1967). Intelligence assessment: A theoretical and experimental approach. British Journal of Educational Psychology, 37, 81-98.

Finn, J. D. (1977). Multivariance: Univariate and multivariate analysis of variance, covariance and regression - version 5.2. Ann Arbor, Ml: National Educational Resources, Inc.

Furneaux, W. D. (1960). Intellectual abilities and problem solving behavior. In H. Eysenck (Ed.), Handbook of abnormal psychology. London: Pitman.

Goldberg, R. A., \& Schwartz, S. (1977). Individual differences in cognitive processes. Journal of Educational Psychology, 69 (1), 9-14.

Heim, A. (1970). Intelligence and personality. New York: Penguin.

Hermelin, B., \& O'Connor, N. (1980). Perceptual, motor and decision speeds in specifically and generally gifted children. Gifted Child Quarterly, 24, 180-185.

Hunt, E., Frost N., \& Lunneborg, C. (1973). Individual differences in cognition: A new approach to intelligence. In G. H. Bower (Ed.), The psychology of learning and motivation (Vol. 7). New York: Academic. 
Hunt, E., Lunneborg, C., \& Lewis, J. (1975). What does it mean to be high verbal? Cognitive Psychology, 7, 194-227.

Jensen, A. R. (1980). Bias in mental testing. New York: Free Press.

Kagan, J., Moss, H. A., \& Siegal, I. E. (1963). Psychological significance of style of conceptualization. In J. C. Wright \& J. Kagan (Eds.), Basic cognitive processes in children. Monographs of the Society of Research in Child Development, 28, Whole No. 2.

Kagan, J., Pearson, L., \& Welch, L. (1966). Conceptual impulsive and inductive reasoning. Child Development, 37, 537-594.

Lord, F. M. (1956). A study of speed factors in tests and academic grades. Psychometrika, 21, 31-50.

McFarland, R. A. (1930). An experimental study of the relationship between speed and mental activity. Journal of General Psychology, 3, 67-97.

Messer, S. B. (1976). Reflection-impulsivity: A review: Psychological Bulletin, 83, 1026-1052.

Miyajima, K. (1972). The analytic study of speed components in intelligence test with time-limits: Proposition of a new approach to the speed and power problem. Psychologia: An International Journal of Psychology in the Orient, 15, 232-239.

Mulholland, T. M., Pellegrino, J. W., \& Glaser, R. (1980). Components of geometric analogy solution. Cognitive Psychology, 12, 252-284.

Pachella, R. G. (1974). The interpretation of reaction time in information processing research. In B. H. Kantowitz (Ed.), Human information processing. Hillsdale, NJ: Erlbaum.

Pellegrino, J. W., \& Glaser, R. Cognitive correlates and components in the analysis of individual differences. In R. J. Sternberg \& D. K. Detterman (Eds.), Human intelligence: Perspectives on its theory and measurement. Norwood, NJ: Ablex.

Pew, R. W. (1969). The speed-accuracy operating characteristic. (Attention and Performance.) Acta Psychologica, 30, 16-26.

Porebski, O. A. (1954). Psychological and statistical study of speed and power as variables of human ability. Occupational Psychology, 28, 218-231.

Porebski, O. A. (1960). Speed and power factors of intelligence: Further evidence. Occupational Psychology, 34.

Snow, R. E. (1978). Theory and method for research on aptitude processes. Intelligence, 2, 225-278.

Spiegal, M. R., \& Bryant, N. D. (1978). Is speed of processing information related to intelligence and achievement? Journal of Educational Psychology, 70 (6), 904-910.

Sternberg, R. J. (1977). Intelligence, information processing and analogical reasoning: The componential analysis of human abilities. Hillsdale, NJ: Erlbaum. 
Sternberg, R. 1. (1984). Toward a triarchic theory of human intelligence. The Behavioral and Brain Sciences, 7, 269-315.

Sternberg, R. J., Conway, B. E., Ketron, J. L., \& Bernstein, M. (1981). People's conceptions of intelligence. Journal of Personality and Social Psychology, 41, 37-55.

Sternberg, R. J., \& Davidson, J. E. (1982). The mind of the puzzler. Psychology, Today, 16, 37-44.

Sternberg, R. J., \& Davidson, J. E. (1983). Insight in the gifted. Educational Psychologist, $18(1), 51-57$.

Thurstone, L. L. (1939). Primary mental abilities. Psychometric Monographs, Whole No. 1.

Thurstone, L. L. (1944). A factorial study of perception. Chicago: University of Chicago Press.

Thurstone, L. L. (1963). Primary mental abilities for grades 9-12, Revised 1962. Chicago: Science Research Associates. 